\title{
Does the fatigue loading frequency affect the lithium disilicate glass ceramic inlay-dentin bond strength?
}

\author{
Flavia Zardo Trindade ${ }^{\mathrm{a}}$, Fernanda Campos ${ }^{\mathrm{b}}$, Caroline Cotes Marinho ${ }^{\mathrm{b}}$, Marco Antonio Bottino ${ }^{\mathrm{b}}$, \\ Luiz Felipe Valandro ${ }^{\mathrm{c}, *}$, Cornelis J. Kleverlaan ${ }^{\mathrm{d}}$ \\ ${ }^{a}$ Department of Dental Materials and Prosthodontics, Araraquara Dental School, Univ Estadual Paulista (UNESP), 1680 Humaitá Street, 14801-903 Araraquara, SP, \\ Brazil \\ b Department of Dental Materials and Prosthodontics, Univ Estadual Paulista (UNESP), Institute of Science and Technology, São José dos Campos Dental School, 777 Eng. \\ Franscisco José Longo Avenue, 12245-000 São José dos Campos, SP, Brazil \\ ${ }^{\mathrm{c}}$ Prosthodontics Unit, Faculty of Odontology, Federal University of Santa Maria, Rio Grande do Sul State, Floriano Peixoto Street, 1184, 97015-372 Santa Maria, RG, \\ Brazil \\ ${ }^{\mathrm{d}}$ Department of Dental Materials Science at ACTA, Universiteit van Amsterdam and Vrije Universiteit, Gustav Mahlerlaan 3004, 1081LA Amsterdam, The Netherlands
}

\section{A R T I C L E I N F O}

\section{Keywords:}

Bond strength

Lithium disilicate

Micro-tensile

Fatigue

Aging

\begin{abstract}
A B S T R A C T
The aim of this study was to verify the effect of loading frequency during mechanical cycling on the microtensile bond strength between tooth and ceramic inlays. Twenty-four extracted permanent maxillary molars were standardly prepared ( $3 \mathrm{~mm}$ wide $\times 4 \mathrm{~mm}$ deep) to receive lithium disilicate-based ceramic inlays. After the adhesive cementation, the restored teeth were divided into three groups $(n=8)$, according to different range of mechanical cycling frequency: control group - water storage, $2.0 \mathrm{~Hz}$ group - mechanical cycling at frequency of $2.0 \mathrm{~Hz}\left(0-100 \mathrm{~N}, 1.2 \times 10^{6}\right.$ cycles, water $\left.37^{\circ} \mathrm{C}\right)$, and $6.7 \mathrm{~Hz}$ group - mechanical cycling at frequency of $6.7 \mathrm{~Hz}$ $\left(0-100 \mathrm{~N}, 1.2 \times 10^{6}\right.$ cycles, water $\left.37^{\circ} \mathrm{C}\right)$. The teeth were then cut into microbars $(1 \times 1 \mathrm{~mm}$, non-trimming method), which were tested under microtensile (MTBS) loading. The failure mode was classified and the data were analyzed by one-way ANOVA. The mean bond strength value of the control group was the highest and the values of the cycled groups were $15 \%$ lower, however the groups were statistically similar $(p=0.58)$. Chi-square test showed no statistical difference among the groups regarding the pre-test failures $(p=0.17)$. For all groups, the most frequent failure type was mode 1 (adhesive at the interface ceramic/cement) and mode 2 (mixed failure). Loading frequencies up to $6.7 \mathrm{~Hz}$ had no effect on the lithium disilicate glass ceramic inlay-dentin bond strength.
\end{abstract}

\section{Introduction}

Since the 1980s the use of ceramic inlays for posterior restorations have been increasing [1-3]. Among the ceramic systems available, the lithium disilicate-based material is even more indicated due to its properties like translucency [4], good adhesion to tooth substrate [5] and higher strength compared to other glass-based ceramics [6].

The lithium disilicate-based ceramic has a well-defined cementation protocol with hydrofluoric acid etching, silanization, and resin cement [7]. In partial restorations, the adhesive cementation promotes a better bond strength between tooth and ceramic, which leads to enhanced marginal adaptation [8] and lower microleakage [9]. Besides that, a good adhesion between tooth and ceramic would enable less possibility for cusp deflection [9] and increases fracture strength [10]. However, the cusp deflection - which is caused by poor bond strength with the tooth, a smaller amount of remaining tooth structure, among other factors - is the main origin of catastrophic failures of teeth restored with inlays. Therefore, in vitro studies must use some fatigue method to attempt to mimic the physiological cyclic stresses caused by the mastication.

Several in vitro studies using mechanical cycling have been performed to predict the survival rate of the materials and restored teeth. However, the parameters used to execute the mechanical cycling, such as occlusal loading, frequency of mechanical pulses and number of cycles, vary a lot among the studies, and there is no consensus regarding these parameters in the literature. Besides that, the correlation between the in vitro chewing simulation and the clinical situation has been widely discussed [11-16]. According to Boever et al. [17],

\footnotetext{
* Corresponding author.

E-mail addresses: flaviazardo@hotmail.com (F.Z. Trindade),cd.fernandacampos@gmail.com (F. Campos), caroline_cotes@yahoo.com.br(C.C. Marinho), mmbottino@uol.com.br (M.A. Bottino), lfvalandro@hotmail.com (L.F. Valandro), c.kleverlaan@acta.nl (C.J. Kleverlaan).
} 
chewing frequency is around about $1 \mathrm{~Hz}$, ranging from 0.5 to $1.3 \mathrm{~Hz}$, while other studies reported frequency rates varying from 1 to $2 \mathrm{~Hz}$ [18-20]. Furthermore, these authors states that the frequency rate during chewing can be influenced by the day, the individual, and the type of food, its consistency and viscosity. Additionally, Jemt et al. [21] observed that the length of the masticatory cycle reduces over the cycles and the maximum vertical movement of the mandible decreased throughout the chewing period. These findings shows how the chewing parameters may vary widely, making difficult to reproduce them accurately on in vitro tests.

Since the correlation between in vitro and in vivo situations is difficult to make, the in vitro simulation of the normal and physiological functional chewing parameters is still a challenge. However, researchers have been trying to mimic them on their in vitro tests by using values of occlusal loading and frequency rate as close as possible to the physiological parameters to produce more clinically relevant results [14,22-28]. Studies [23,25,28-30] involving mechanical cycling (aging protocol) and bond strength degradation of adhesive interfaces have used a frequency rate between 1 to $4 \mathrm{~Hz}$.

However, there is still limited information in the literature regarding the effect of frequency rate on the results of in vitro studies involving mechanical cycling or fatigue tests and bond strength degradation, especially concerning the influence of a higher and nonphysiological frequency. Therefore, since there is no consensus in the literature about the frequency rate that should be used in mechanical cycling methodology and there is a great variety on the frequency rate protocol, the present study aimed to evaluate the effect of different loading frequencies - $2 \mathrm{~Hz}$ compared to a higher one $(6.7 \mathrm{~Hz})-$ of mechanical cycling, on the microtensile bond strength between tooth and lithium disilicate glass ceramic inlays cemented to molars. The null hypothesis was that the loading frequency would not affect the bond strengths results.

\section{Materials and methods}

The materials (brand, and chemical composition) used are summarized in Table 1.

\subsection{Experimental design}

Maxillary molars and respective inlay restorations were assigned into 3 groups according to the frequency used for mechanical cycling of the assembly: a control group without applying repeated loading; frequency of 2.0 or $6.7 \mathrm{~Hz}$. After the microtensile test, the 'tooth' was considered as the experimental unit.

\subsection{Cavity preparations and ceramic inlay production}

Twenty-four permanent maxillary molars, without visible cracks, were selected and randomly divided into three groups $(n=8)$. The roots of each specimen were embedded in a plastic cylinder filled with chemically cured acrylic resin (Dencrilay, Dencril, Caieiras, SP, Brazil) up to $2 \mathrm{~mm}$ from the cervical line in the apical direction. A surveyor was used to place the root perpendicularly to the y-axis. Standardized inlay preparations $(3.0 \mathrm{~mm}$ wide $\times 4.0 \mathrm{~mm}$ deep), with a rectangular shape and a non-proximal box, were created in all teeth (Fig. 1). A highspeed hand piece with a conical trunk diamond bur with rounded angles (KG Sorensen 3131, Barueri, Brazil) fixed to a modified optic microscope was used for optimal standardization of preparations (Fig. 1). This device (modified optical microscope), limited the movements of the high-speed hand piece, which prevented differences in buccal-palatal width and cusp thickness of the teeth, and all cavities could be created on a standardized and reproducible manner. Impressions of the prepared teeth were made using polyvinyl siloxane (Elite, Zhermack, Badia Polesine, Italy) and stone master dies were created. Ceramic inlays were made of IPS e-max Press (Ivoclar Vivadent, Schaan, Liechtenstein).

\subsection{Inlays cementation}

Firstly, the inner surfaces of the inlays were etched with $10 \%$ hydrofluoric acid (Dentsply, Petrópolis, RJ, Brazil) for $20 \mathrm{~s}$, while teeth preparations were etched with $35 \%$ phosphoric acid (Adper Scothbond, 3M/ESPE, St Paul, MN, USA) for $15 \mathrm{~s}$. The treated surfaces were rinsed with water, dried and a silane coupling agent (RelyX Ceramic Primer, 3M/ESPE) was applied on the ceramic surfaces and two layers of an adhesive system (Adapter ${ }^{\mathrm{TM}}$ Single Bond, 3M/ESPE) on the dentin surface. The resin cement (Rely X ARC, 3M/ESPE) was mixed and applied to the inner surfaces of the inlays and seated using finger pressure. Excess cement was removed and each specimen was light cured (Elipar FreeLight 2, 3M/ESPE) at the buccal, lingual and occlusal surfaces $(3 \times$ 40 s). All procedures were carried out according to manufacturers instructions.

\subsection{Mechanical cycling}

The specimens were stored for $24 \mathrm{~h}$ in distilled water at $37{ }^{\circ} \mathrm{C}$ and then subjected to mechanical cycling using a chewing simulator (Fatigue Tester, ACTA, University of Amsterdam, Netherland). The specimens were placed inside this machine, which is composed by a tub bath containing distillated water at $37^{\circ} \mathrm{C}$ and 10 metallic cylinder pistons with a $6 \mathrm{~mm}$ round shape tip. The load was applied vertically on the specimens, specifically positioning on both cusps, at the area between the top of the cusp and the restoration margin, without direct contact to the ceramic restoration (Fig. 2). A load of 10 to $100 \mathrm{~N}$ was applied at a frequency of 2.0 or $6.7 \mathrm{~Hz}$ for $1,200,000$ cycles $(167 \mathrm{~h}$ or $50 \mathrm{~h}$ ). All groups were kept stored in water at $37^{\circ} \mathrm{C}$ for the same period (a total of $167 \mathrm{~h}$ ) before cutting them into microbars.

Table 1

Type, brand, and main chemical composition of the materials used.

\begin{tabular}{|c|c|c|}
\hline Material type & Name/Brand & Chemical composition $^{\mathrm{a}}$ \\
\hline Ceramic blocks & $\begin{array}{l}\text { e.Max Press (Ivoclar Vivadent, Schaan, } \\
\text { Liechtenstein) }\end{array}$ & Lithium-disilicate based glass ceramic \\
\hline Hydrofluoric acid & $\begin{array}{l}\text { 10\% Hydrofluoric acid (Dentsply, Petrópolis, } \\
\text { Brazil) }\end{array}$ & $10 \%$ Hydrofluoric acid by weight, water, stabilizers \\
\hline Phosphoric acid & $\begin{array}{l}\text { Adper Scotchbond 35\% ( } 3 \text { M/ESPE, St. Paul, MN, } \\
\text { USA) }\end{array}$ & $35 \%$ Phosphoric acid by weight, water, stabilizers \\
\hline Adhesive resin & $\begin{array}{l}\text { Adper }^{\mathrm{TM}} \text { Single Bond ( } 3 \mathrm{M} / \mathrm{ESPE}, \text { St. Paul, MN, } \\
\text { USA) }\end{array}$ & bis-GMA, polyalkenoic acid, copolymer, dimethacrylates, HEMA, photoinitiators, ethanol, water \\
\hline Silane coupling agent & $\begin{array}{l}\text { RelyX Ceramic Primer ( } 3 \text { M/ESPE, St. Paul, MN, } \\
\text { USA) }\end{array}$ & hydrolyzed y-methacryloxypropyltrimetoxy-silane \\
\hline Resin cement & RelyX ARC (3 M/ESPE, St. Paul, MN, USA) & $\begin{array}{l}\text { Bis-GMA, TEGDMA, dimethacrylate polymer, zirconia/silica glass ( } 67.5 \mathrm{wt} \%) \text {, chemical, and } \\
\text { photoinitiators. }\end{array}$ \\
\hline
\end{tabular}

\footnotetext{
${ }^{\text {a }}$ Data from manufacturer.
} 

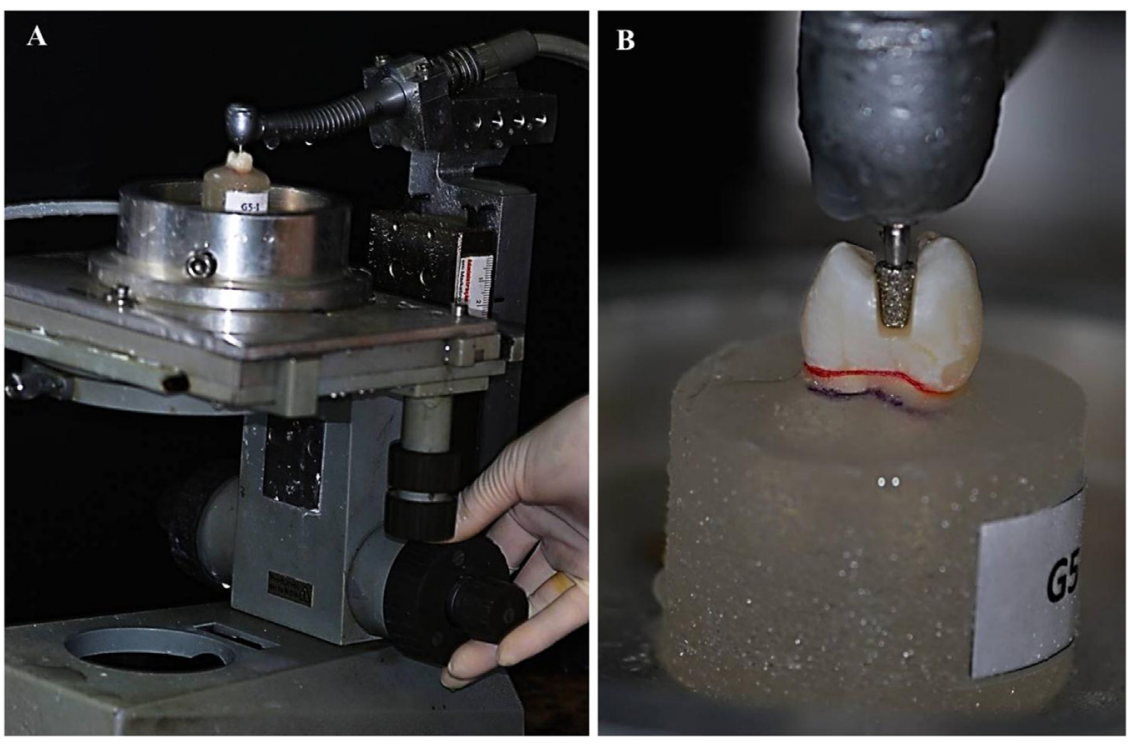

Fig. 1. Illustration of the MOD inlay preparation.

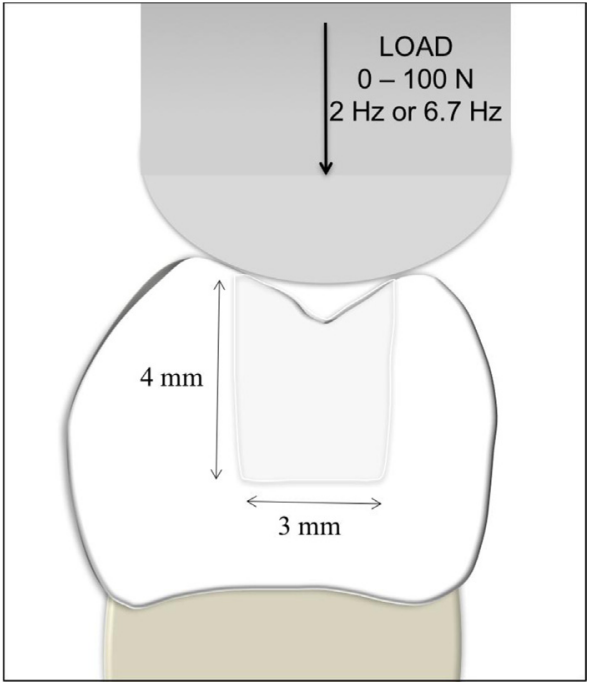

Fig. 2. Schematic picture of the load application on the tooth. It notes that the load is applied on the slope of the cusps (no loading on the restoration).

\subsection{Microtensile test}

The crowns were sectioned in longitudinal (bucco-lingually) and transversal (mesio-distally) axes, using a cutting machine (Isomet 1000, Buehler, Lake Bluff, IL, USA) and $0.3 \mathrm{~mm}$ thick diamond disc to produce microbars specimens $(1 \times 1 \mathrm{~mm})$. The microbars specimens were composed of buccal dentin, ceramic in the middle and lingual dentin (Fig. 3). An average of 6 microbars were obtained from each tooth, which were submitted to the microtensile bond strength test [31]. The load at failure was recorded using a universal testing machine (EMIC DL-2000, EMIC, São José dos Pinhais, PR, Brazil) at a crosshead speed of $0.5 \mathrm{~mm} / \mathrm{min}$. The bond strength "R" (MPa) was calculated by dividing the maximum load for the specimen failure $(\mathrm{N})$ by the cross sectional interfacial area $\left(\mathrm{mm}^{2}\right)$, measured with a digital caliper before test $(\mathrm{R}=\mathrm{F} / \mathrm{A})$, for each specimen.

\subsection{Failure analysis}

After the microtensile test, the fractured surfaces were examined under a stereomicroscope $(50 \times$ magnification; Discovery V.20, Carl-
Zeiss, Gottingen, Germany) and the failure mode was classified as one of the following:

1. Interfacial adhesive at ceramic/cement interface (more than $75 \%$ );

2. Mixed failures, in which the failures were recorded as the surfaces comprising the dominance of failure of each substrate;

3. Interfacial adhesive at cement/dentin interface (more than $75 \%$ ).

\subsection{Data analysis}

For the statistical analysis, the experimental unit considered in this study was the tooth. Therefore, the values obtained by each microbar were averaged to provide a single value per tooth. The bond-strength mean values in each group were represented by the sum of the eight experimental units. The specimens that failed prior to testing were considered in the statistical analysis to provide a fair comparative evaluation among the groups. For this purpose, an arbitrary number, which was the minimum value of microtensile obtained in each group, was assigned to each prematurely debonded specimen [30,32-35]. Data were subjected to normality (Shapiro-Wilk) and homoscedasticity (Barllet's) test. Since data presented a normal distribution and equality of variances, parametric test was performed. The effect of frequency on bond strength among the groups was analyzed by one-way ANOVA with a post hoc Tukey test $(\alpha=0.05)$. Differences of occurrence range of pretest failure inside the groups were indicated by Chi-square test $(\alpha<0.05)$. Differences between the groups regarding the failure mode classification were analyzed by one-way ANOVA (by Ranks).

\section{Results}

The number of specimens tested, mean bond strength and their standard deviation, besides the percentage of pre-test failures occurred during the cutting procedures, are listed in Table 2. Although the mean nominal bond strength value of the control group was the highest and the values of the cycled groups was $15 \%$ lower, the groups were statistically similar $(p=0.58)$.

The control group showed lower percentage of pre-test failures than mechanical cycling groups, however this difference was not statistically significant. Fig. 4 shows the rates of pre-test failures and tested specimens in each experimental group. Chi-square test showed no statistical difference among the groups regarding these rates $(p=0.17)$.

For all groups, the most frequent failure type was mode 1 (adhesive at the interface ceramic/cement) and mode 2 (mixed failure). A higher 


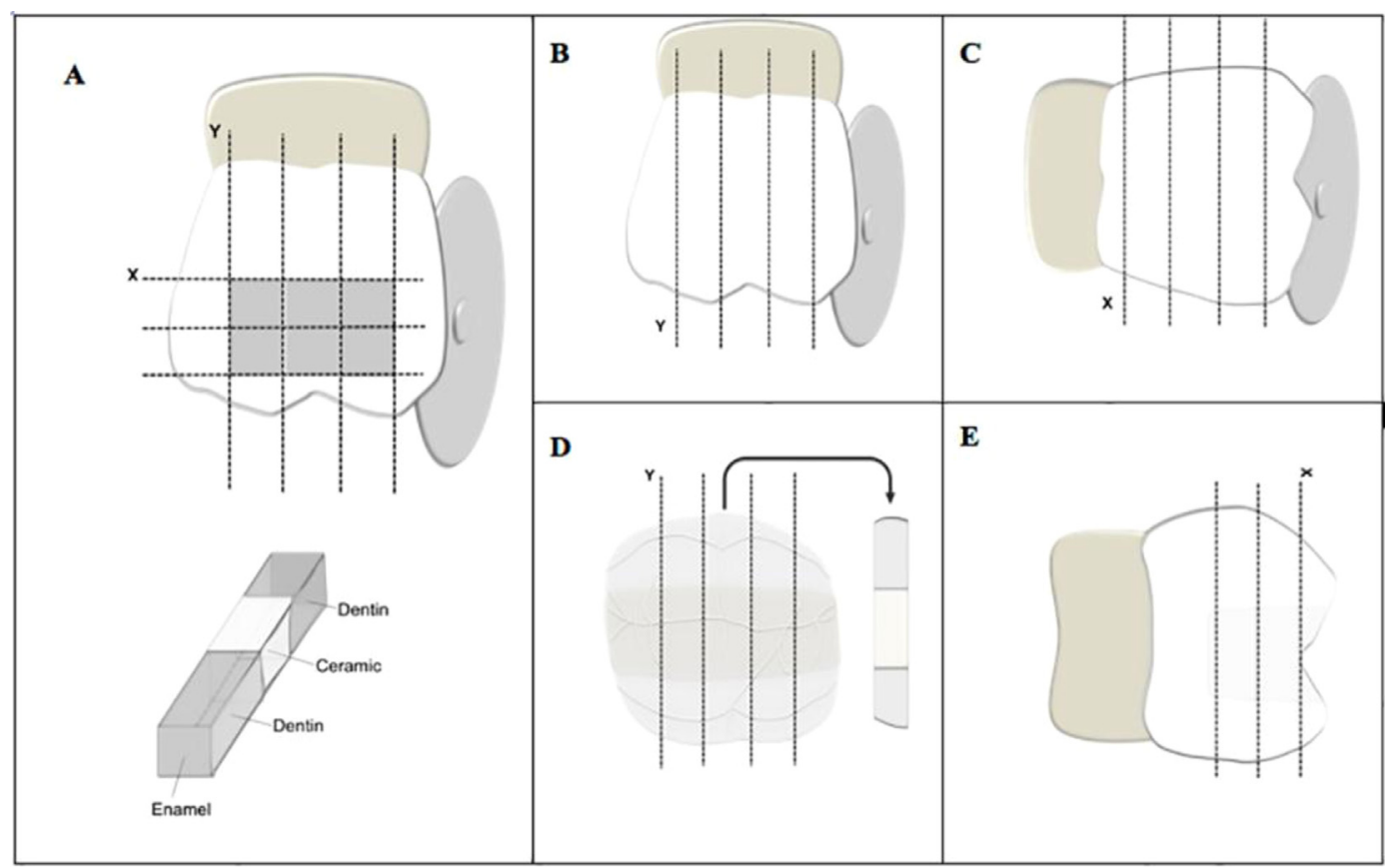

Fig. 3. Schematic illustration of the cutting procedure of the teeth to produce the bar specimens. A - The crown with the longitudinal and transverse axis of cutting procedure to produce bar specimens characterized with a non-trimmed interface and composed of buccal dentin, ceramic in the middle and lingual dentin. B - Frontal view of the crown has been sectioned first in the longitudinal axis (bucco-lingually). C - Frontal view of the crown as sectioned second in the transverse axis (mesiodistally). D - Occlusal view of the crown sectioned first in the longitudinal axis (bucco-lingually). E - Lateral view of the crown as sectioned second in the transversal axis (mesio-distally).

Table 2

Mean and standard deviation (SD) of bond strength according to the groups together with the percentage of pre-test failures.

\begin{tabular}{llll}
\hline Groups & Specimens & Mean \pm SD & Pre-failure (\%) \\
\hline Control & 52 & $22.0 \pm 5.7 \mathrm{~A}$ & $5(9.6 \%)$ \\
$2.0 \mathrm{~Hz}$ & 56 & $19.2 \pm 7.1 \mathrm{~A}$ & $15(26.7 \%)$ \\
$6.7 \mathrm{~Hz}$ & 52 & $19.3 \pm 5.4 \mathrm{~A}$ & $13(25.0 \%)$ \\
\hline
\end{tabular}

*Capital letters represent no statistical differences between the groups $(\mathrm{P}>0.05)$.

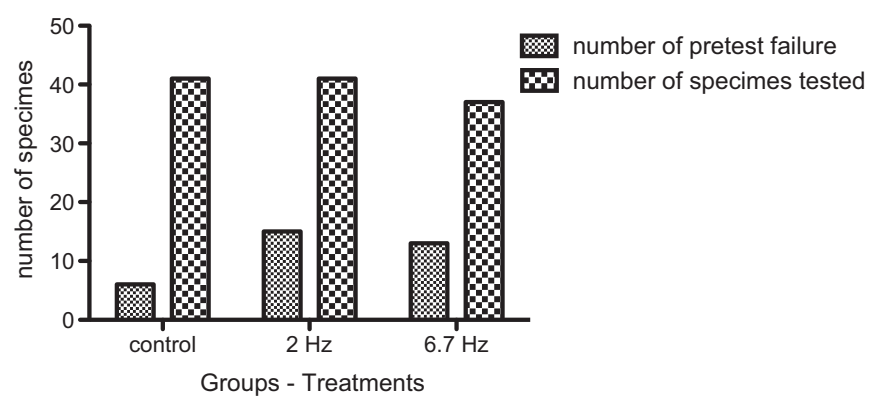

Fig. 4. Columns represent the pre-test failures and tested specimens' rates in each study group.

percentage of mode 1 failure was observed in groups submitted to the mechanical cycling $(2.0 \mathrm{~Hz}$ and $6.7 \mathrm{~Hz}$ groups) than the control group, however no statistical difference was indicated by one-way ANOVA (by Rank) among the groups ( $p=0.11)$ (Fig. 5).

\section{Discussion}

The aim of the present study was to evaluate the influence of different loading frequencies of mechanical cycling, used as aging protocol, on the microtensile bond strength between tooth and lithium

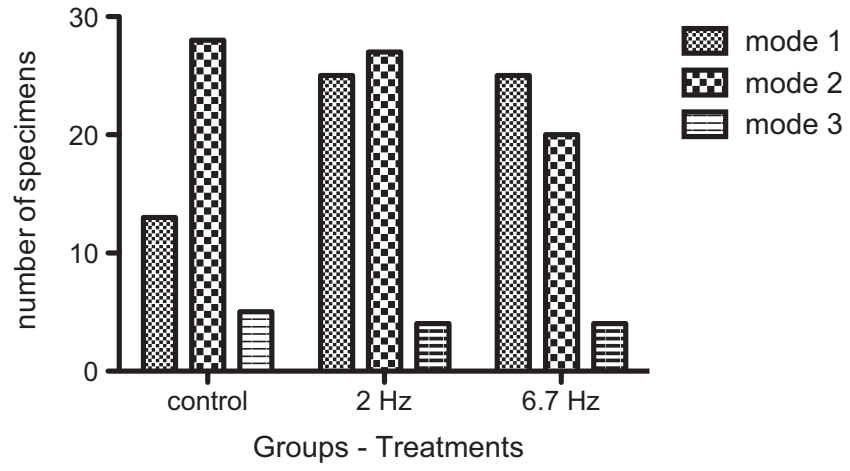

Fig. 5. Columns represent the rate of each failure mode in each experimental group.

disilicate glass ceramic inlays adhesively cemented to molars. After loading the cusps with $100 \mathrm{~N}$ for 1,200,000 cycles, at the 2 and $6.7 \mathrm{~Hz}$, the bond strength between the tooth and the restoration did not change significantly in comparison to the control, and no significant statistical difference was observed between the two applied loading frequencies. Although there was an overall trend that both fatigue groups had a lower bond strength, more pre-failures, and more adhesive/cement failures, compared to the control group.

The bond strength values $(19.2 \pm 7.1-22.0 \pm 5.7 \mathrm{MPa})$ were similar to other studies that evaluated MTBS between lithium-disilicate glass ceramic and resin cement $(19.3 \pm 4.2 \mathrm{MPa}$ to $35.0 \pm 9.6)[5,36-38]$. Guarda et al. [37], which also investigated the MTBS of lithium-disilicate glass ceramic (IPS e.max Press, Ivoclar Vivadent) to dual-cured resin cement, under aging conditions (fatigue and thermocycling), observed as results of bond strength $35.0 \pm 9.6 \mathrm{MPa}$ for control group and $24.3 \pm 8.9 \mathrm{MPa}$ for the fatigue group, even under ideal geometric situations.

Although several in vitro studies [14,22-30,33,39] using fatigue loading have been performed to predict the survival rate of restored 
teeth, no consensus about its parameters can be found in the literature. These parameters include applied load, number and frequency of mechanical cycles. In vivo, loading frequency at chewing is a characteristic of each individual and varies widely from one individual to another [20]. It also depends on the type of food $[18,20]$, size of food bolus and hardness and rheological characteristics of the food [20], which in general results in a frequency rate of $1.2-1.6 \mathrm{~Hz}[18,21]$. Based on this, for laboratorial tests, it is recommended that loading should be limited to $2 \mathrm{~Hz}$ in order to simulate clinically relevant damage accumulation [40].

As result of fatigue loading, failures might occur such as fractures, loss of compliance, or wear, which is often influenced by environmental factors [41]. The bonded interface between material and tooth is much more sensitive to the presence of flaws and susceptible to fatigue crack growth that initiates from existing defects [42]. Changes in this interface may be exacerbated by flexure of the restored tooth under occlusal stresses [43], especially in inlay restorations, which are exposed to cusp deflection. When the cusps are not completely covered by the restoration, it might results in a potential production of large marginal gaps and microleakage between remaining tooth and restorative material [44-46]. Therefore, good adhesion between tooth and restoration could protect the tooth from suffering microleakage and cuspal deflection $[45,47]$. The damage caused by fatigue loading on bonding interface was observed by Saavedra et al. [39]. The authors evaluate the effect of mechanical cycling on microtensile bond strength in premolars restored with ceramic inlays, and the bond strength was significantly reduced in the groups submitted to fatigue loading. On the other hand, Trindade et al. [28], which also evaluated the effect of the fatigue loading on bonding interface in premolars restored with ceramic inlays, observed that the mechanical cycling did not significantly reduced the microtensile bond strength values.

In the present study, it was supposed that the groups submitted to the mechanical cycling could present lower microtensile bond strength values compared to the control group. In fact, the loaded groups presented lower MTBS values, however, no statistical difference was observed among those groups in comparison to the control group. This result suggests that the adhesion between lithium-disilicate ceramic/ cement/dentin was sufficiently strong to tolerate the fatigue duration and loading, or the protocol used to load the specimen was not aggressive enough to produce significant degradation of the adhesive interface. Saavedra et al. [39], which showed a significant decrease in bond strength between ceramic inlays and dentin after fatigue, used $50 \mathrm{~N}$ of load, $8 \mathrm{~Hz}$ of frequency, and 1,400,000 cycles, as protocol. On the other hand, Feitosa et al. [33], which also evaluated the microtensile bond strength between ceramic inlays and dentin after mechanical cycling $(100 \mathrm{~N}, 4 \mathrm{~Hz}, 2,000,000$ cycles), observed that mechanical cycling did not affect the bond strength between ceramic and dentin [33]. This result is in agreement with the results observed by Trindade et al. [28], which also investigated the effect of mechanical cycling $(100 \mathrm{~N}, 2 \mathrm{~Hz}, 1,200,000$ cycles) on the microtensile bond strength between ceramic inlays and dentin. However, since the fatigue loading protocol used in these studies were different from those that we used, comparisons are difficult to make. In turn, it seems that physiological or smaller loads when applied at high frequencies $(8 \mathrm{~Hz})$ could cause damage to the adhesive interface. On the other hand, physiological loads at a frequency closer to physiological would not cause significant damage to the adhesive interface, even when a much higher number of cycles $(2,000,000$ cycles $)$ is used. In a clinical setting, it can be speculated that, since it is not possible to increase the chewing frequency rate, the damage in the adhesive interfaces could be caused by an overloading situation.

Recently, Takamizawa et al. [48] investigated the influence of frequency on shear fatigue strength (SFS) of resin composite to enamel using both 5 and $20 \mathrm{~Hz}$ frequencies, for 50,000 cycles, but no significant difference in SFS was found between both frequencies. In another recent study, Scheidel et al. [49] also examined the effect of different frequencies $(5,10$, and $20 \mathrm{~Hz}$ ) for 50,000 cycles on shear fatigue strength between resin composite and dentin, using three self-etch adhesives. The authors did not observe any significant differences in SFS in the adhesives between the three frequencies. These results confirm the lack of significant influence of different frequency rates on the bond strength that was observed in the present study. However, the experimental scenario of the present study was completely different from both prior studies, in which the shear bond strength test was used on geometric samples, while we used the microtensile test on molars restored with glass ceramic inlays, preliminarily aged by mechanical cycling. The mechanical cycling was performed on the restored molars as an aging protocol to mimic the clinical situation that the materials are submitted to produce more clinically relevant results. Besides that, it is important to emphasize that the microtensile bond strength test presents the advantage of producing more reliable results than the shear bond strength test [50]. The shear bond strength test has been criticized due to the heterogeneity of the distribution of the stress in the adhesive interface. The higher occurrence of cohesive failures in this kind of test reveals that the substrate might be under greater stress concentration than the adhesive interface [50], while the microtensile test, which was introduced in the $90 \mathrm{~s}$ to evaluate bond strength to dentin using small areas, allows better stress distribution during the test [31].

The lack of significant damage caused by fatigue on the bond strength observed in the present study was also confirmed by the failure mode analyses. Although an influence of the fatigue protocol seems to have happened, with a higher rate of adhesive failure at the ceramic/ cement interface in the loaded groups, no statistical difference could be observed. It means that the adhesive interface failure mode was affected in a similar way by the loading regardless the frequency rate.

In summary, the fatigue protocol used was not able to cause a significant damage in the bond strength between ceramic and restored tooth. Therefore, based on our results, it could be possible to perform the fatigue loading in a shorter time using a higher frequency $(\sim 10 \mathrm{~Hz})$. This experiment with $100 \mathrm{~N}$ for $1,200,000$ cycles may represent a clinical situation of $1-3$ years $[14,16]$. Since there was no effect of the fatigue loading compared to the control, it seems that failure of lithium disilicate glass ceramic inlays is due to overloading or inadequate bonding procedures. Furthermore, using a high frequency mode $(\sim 10 \mathrm{~Hz})$, long-term fatigue regimen can be run to predict longer lifetimes of restorative conditions.

\section{Conclusion}

Within the limitations of this study, it could be concluded that frequencies up to $6.7 \mathrm{~Hz}$ for fatigue loading had no influence in the microtensile bond strength between tooth and lithium disilicate glass ceramic inlays.

\section{Acknowledgments}

The authors thank the São Paulo Research Foundation (FAPESP grants \#2010/51827-4 and 2010/07237-8) for financial support to conduct this study.

\section{References}

[1] Banks RG. Conservative posterior ceramic restorations: a literature review. J Prosthet Dent 1990;63:619-26.

[2] Qualtrough AJ, Wilson NH, Smith GA. Porcelain inlay: a historical view. Oper Dent 1990;15:61-70.

[3] Kelly JR, Nishimura I, Campbell SD. Ceramics in dentistry: historical roots and current perspectives. J Prosthet Dent 1996;75:18-32.

[4] Stappert CF, Denner N, Gerds T, Strub JR. Marginal adaptation of different types of all-ceramic partial coverage restorations after exposure to an artificial mouth. $\mathrm{Br}$ Dent J 2005;199:779-83.

[5] Marocho SM, Ozcan M, Amaral R, Bottino MA, Valandro LF. Effect of resin cement type on the microtensile bond strength to lithium disilicate ceramic and dentin using different test assemblies. J Adhes Dent 2013;15:361-8. 
[6] Gorman CM, Horgan K, Dollard RP, Stanton KT. Effects of repeated processing on the strength and microstructure of a heat-pressed dental ceramic. J Prosthet Dent 2014;112:1370-6.

[7] Brentel AS, Ozcan M, Valandro LF, Alarca LG, Amaral R, Bottino MA. Microtensile bond strength of a resin cement to feldpathic ceramic after different etching and silanization regimens in dry and aged conditions. Dent Mater 2007;23:1323-31.

[8] van Dijken JW, Horstedt P. Marginal breakdown of fired ceramic inlays cemented with glass polyalkenoate (ionomer) cement or resin composite. J Dent 1994;22:265-72.

[9] El Zohairy AA, De Gee AJ, Mohsen MM, Feilzer AJ. Microtensile bond strength testing of luting cements to prefabricated CAD/CAM ceramic and composite blocks. Dent Mater 2003;19:575-83.

[10] Heintze SD, Cavalleri A, Zellweger G, Buchler A, Zappini G. Fracture frequency of all-ceramic crowns during dynamic loading in a chewing simulator using different loading and luting protocols. Dent Mater 2008;24:1352-61.

[11] DeLong R, Sakaguchi RL, Douglas WH, Pintado MR. The wear of dental amalgam in an artificial mouth: a clinical correlation. Dent Mater 1985;1:238-42.

[12] Kern M, Strub JR, Lu XY. Wear of composite resin veneering materials in a dual-axis chewing simulator. J Oral Rehabil 1999;26:372-8.

[13] Krejci I, Lutz F, Reimer M, Heinzmann JL. Wear of ceramic inlays, their enamel antagonists, and luting cements. J Prosthet Dent 1993;69:425-30.

[14] Rosentritt M, Behr M, van der Zel JM, Feilzer AJ. Approach for valuating the influence of laboratory simulation. Dent Mater 2009;25:348-52.

[15] Stappert CF, Att W, Gerds T, Strub JR. Fracture resistance of different partial-coverage ceramic molar restorations: an in vitro investigation. J Am Dent Assoc 2006;137:514-22.

[16] Wiskott HW, Nicholls JI, Belser UC. Stress fatigue: basic principles and prosthodontic implications. Int J Prosthodont 1995;8:105-16.

[17] De Boever JA, McCall Jr. WD, Holden S, Ash Jr. MM. Functional occlusal forces: an investigation by telemetry. J Prosthet Dent 1978;40:326-33.

[18] Hiiemae K, Heath MR, Heath G, Kazazoglu E, Murray J, Sapper D, et al. Natural bites, food consistency and feeding behaviour in man. Arch Oral Biol 1996;41:175-89.

[19] Buschang PH, Hayasaki H, Throckmorton GS. Quantification of human chewingcycle kinematics. Arch Oral Biol 2000;45:461-74.

[20] Woda A, Mishellany A, Peyron MA. The regulation of masticatory function and food bolus formation. J Oral Rehabil 2006;33:840-9.

[21] Jemt T, Karlsson S, Hedegard B. Mandibular movements of young adults recorded by intraorally placed light-emitting diodes. J Prosthet Dent 1979;42:669-73.

[22] Guess PC, Vagkopoulou T, Zhang Y, Wolkewitz M, Strub JR. Marginal and internal fit of heat pressed versus CAD/CAM fabricated all-ceramic onlays after exposure to thermo-mechanical fatigue. J Dent 2014;42:199-209.

[23] Zamboni SC, Nogueira L, Bottino MA, Sobrinho LC, Valandro LF. The effect of mechanical loading on the cusp defection of premolars restored with direct and indirect techniques. J Contemp Dent Pract 2014;15:75-81.

[24] Zaruba M, Kasper R, Kazama R, Wegehaupt FJ, Ender A, Attin T, et al. Marginal adaptation of ceramic and composite inlays in minimally invasive mod cavities. Clin Oral Investig 2014;18:579-87.

[25] Aguiar TR, Andre CB, Correr-Sobrinho L, Arrais CA, Ambrosano GM, Giannini M. Effect of storage times and mechanical load cycling on dentin bond strength of conventional and self-adhesive resin luting cements. J Prosthet Dent 2014;111:404-10.

[26] Rosentritt M, Sawaljanow A, Behr M, Kolbeck C, Preis V. Effect of tooth brush abrasion and thermo-mechanical loading on direct and indirect veneer restorations. Clin Oral Investig 2015;19:53-60.

[27] Kammermeier A, Rosentritt M, Behr M, Schneider-Feyrer S, Preis V. In vitro performance of one- and two-piece zirconia implant systems for anterior application. J Dent 2016;53:94-101.

[28] Trindade FZ, Kleverlaan CJ, da Silva LH, Feilzer AJ, Cesar PF, Bottino MA, et al. Ceramic inlays: effect of mechanical cycling and ceramic type on restoration-dentin bond strength. Oper Dent 2016;41:E102-17.

[29] Bergoli CD, Amaral M, Boaro LC, Braga RR, Valandro LF. Fiber post cementation strategies: effect of mechanical cycling on push-out bond strength and cement polymerization stress. J Adhes Dent 2012;14:471-8.

[30] Prochnow EP, Amaral M, Bergoli CD, Silva TB, Saavedra G, Valandro LF. Microtensile bond strength between indirect composite resin inlays and dentin: effect of cementation strategy and mechanical aging. J Adhes Dent 2014;16:357-63.

[31] Sano H, Shono T, Sonoda H, Takatsu T, Ciucchi B, Carvalho R, et al. Relationship between surface-area for adhesion and tensile bond strength - evaluation of a microtensile bond test. Dent Mater 1994;10:236-40.

[32] Balducci I, Pagani C, Barcellos DC, Cardoso MV. Microtensile test in dental research. controversial aspects in statistical analysis (experimental unit and premature failures). Braz Dent Sci 2013;16:7-17.

[33] Feitosa SA, Corazza PH, Cesar PF, Bottino MA, Valandro LF. Pressable feldspathic inlays in premolars: effect of cementation strategy and mechanical cycling on the adhesive bond between dentin and restoration. J Adhes Dent 2014;16:147-54.

[34] Vanderlei A, Bottino MA, Valandro LF. Evaluation of resin bond strength to yttriastabilized tetragonal zirconia and framework marginal fit: comparison of different surface conditionings. Oper Dent 2014;39:50-63.

[35] Druck CC, Pozzobon JL, Callegari GL, Dorneles LS, Valandro LF. Adhesion to Y-TZP ceramic: study of silica nanofilm coating on the surface of Y-TZP. J Biomed Mater Res B Appl Biomater 2015;103:143-50.

[36] Aboushelib MN, Sleem D. Microtensile bond strength of lithium disilicate ceramics to resin adhesives. J Adhes Dent 2014;16:547-52.

[37] Guarda GB, Correr AB, Goncalves LS, Costa AR, Borges GA, Sinhoreti MAC, et al. Effects of surface treatments, thermocycling, and cyclic loading on the bond strength of a resin cement bonded to a lithium disilicate glass ceramic. Oper Dent 2013;38:208-17.

[38] Saker S, Alnazzawi A, Ozcan M. Adhesive strength of self-adhesive resins to lithium disilicate ceramic and dentin: effect of dentin chelating agents. Odontology 2016;104:53-9.

[39] Saavedra G, Ariki EK, Federico CD, Galhano G, Zamboni S, Baldissara P, et al. Effect of acid neutralization and mechanical cycling on the microtensile bond strength of glass-ceramic inlays. Oper Dent 2009;34:211-6.

[40] Karl M, Kelly JR. Influence of loading frequency on implant failure under cyclic fatigue conditions. Dent Mater 2009;25:1426-32.

[41] Baran G, Boberick K, McCool J. Fatigue of restorative materials. Crit Rev Oral Biol Med 2001;12:350-60.

[42] Soappman MJ, Nazari A, Porter JA, Arola D. A comparison of fatigue crack growth in resin composite, dentin and the interface. Dent Mater 2007;23:608-14.

[43] Sano H, Yoshikawa T, Pereira PN, Kanemura N, Morigami M, Tagami J, et al. Longterm durability of dentin bonds made with a self-etching primer, in vivo. J Dent Res 1999;78:906-11.

[44] Panitvisai P, Messer HH. Cuspal deflection in molars in relation to endodontic and restorative procedures. J Endod 1995;21:57-61.

[45] Palin WM, Fleming GJ, Nathwani H, Burke FJ, Randall RC. In vitro cuspal deflection and microleakage of maxillary premolars restored with novel low-shrink dental composites. Dent Mater 2005;21:324-35.

[46] St-Georges AJ, Sturdevant JR, Swift Jr. EJ, Thompson JY. Fracture resistance of prepared teeth restored with bonded inlay restorations. J Prosthet Dent 2003;89:551-7.

[47] Costa A, Xavier T, Noritomi P, Saavedra G, Borges A. The influence of elastic modulus of inlay materials on stress distribution and fracture of premolars. Oper Dent 2014;39:160-70.

[48] Takamizawa T, Scheidel DD, Barkmeier WW, Erickson RL, Tsujimoto A, Latta MA, et al. Influence of frequency on shear fatigue strength of resin composite to enamel bonds using self-etch adhesives. J Mech Behav Biomed Mater 2016;62:291-8.

[49] Scheidel DD, Takamizawa T, Bakmeier WW, Erickson RL, Tsujimoto A, Miyazaki M. Effect of frequency on the fatigue strength of dentin bonds. J Oral Sci 2016;58:539-46.

[50] Braga RR, Meira JB, Boaro LC, Xavier TA. Adhesion to tooth structure: a critical review of "macro" test methods. Dent Mater 2010;26:38-49. 